CUAD. CONTAB. / BOCOTÁ, COLOMBIA, 16 (41): 307-328 / MAYO-ACOSTO 2015 / 307

\title{
Lectoescritura y pensamiento crítico: desafío de la educación contable*
}

doi:10.11144/Javeriana.cc16-41.lpcd

\section{William Rojas-Rojas, PhD}

Doctor en Ciencias de Gestión en el Conservatoire

National des Arts et Métiers, CNAM. DEA en desarrollo

de recursos humanos, CNAM. MSc en organizaciones,

contador público y licenciado en filosofía, Universidad del

Valle. Profesor de tiempo completo del programa de conta-

duría pública, Universidad del Valle. Director del grupo de

investigación Nuevo Pensamiento Administrativo. Miem-

bro académico del Centro Colombiano de Investigaciones

Contables C-Cinco.

Correo electrónico: william.rojas@correounivalle.edu.co

\footnotetext{
* Este trabajo se desarrolló a lo largo de más de dos años. Por esta razón, algunas de las ideas expresadas ya han sido expuestas en diferentes espacios académicos y se fueron afinando, a partir de las preguntas que se plantearon. Los avances de este trabajo se presentaron en el II Foro de Estudiantes y Egresados de Contaduría Pública, organizado por el Consejo Estudiantil de Contaduría Pública (COESCO), de la Universidad del Quindío, que se llevó a cabo en 2013; en el Encuentro Nacional de Ensayo Contable, organizado por la Universidad de Antioquia, en 2012 y en otros seminarios universitarios a los cuales me han invitado, como el de la Universidad del Valle, sede Caicedonia, y la Universidad Surcolombiana, Huila.
} 
Resumen Este texto defiende la formación para el pensamiento crítico que se ancla en un campo de disertación que vincula la dignidad humana con el desarrollo de la disciplina contable. A partir de un trabajo documental y una problematización contextual, se examina cómo el pensar-vivir hipermoderno desechó el poder de la razón crítica como un medio fundamental para promover proyectos ético-políticos orientados hacia el reconocimiento de miles de seres humanos que en la actualidad son excluidos y desechados por y desde los postulados del modelo neoliberal globalizado. Se describe cómo las contradicciones socioeconómicas del modelo de desarrollo imperante exigen que los programas de Contaduría Pública repiensen sus Proyectos Educativos (PE) para descifrar cómo pueden salir al encuentro de sus estudiantes y acompañarlos en su proceso de formación. Se concluye que la simple lectoescritura funcional, ajena al pensamiento crítico, lleva a la emergencia del computatōris globalizzatus que no pueden fácilmente articular su saber y sus experticias profesionales a las necesidades de su sociedad. Se finaliza proponiendo unas recomendaciones que faciliten proyectar las reformas a los PE y a los desarrollos de las maestrías en contabilidad.

Palabras clave Formación; universidad; lectoescritura crítica; pensar-vivir hipermoderno; saber; pensamiento crítico

\section{Código JEL M41, M49}

\section{Reading, Writing, and Critical Thought: A Challenge for Accounting Education}

\footnotetext{
Abstract This texts defends education for critical thought based on a dissertation field that links human dignity with the development of the accounting discipline. Based on a documentary work and context-based problem formulation, we examine how hyper-modern thoughtlifestyle cast aside the power of critical reasoning as a fundamental means to promote ethical-political projects. The aim of said projects would be the acknowledgement of
}

thousands of human beings that are currently excluded and rejected by and from the postulates of the globalized neoliberal model. We describe how the socio-economic contradictions of the prevailing development model demand that the Public Accounting programs re-think their Educational Projects (EP) to discover how can they go and meet their students to assist them in their training process. We conclude that simple functional reading and writing, divorced from critical thinking, leads to an emergency of the computatōris globalizzatus, which cannot easily articulate its knowledge and professional expertise to the needs of its society. We conclude by proposing several recommendations leading to make easier the reform of the EP and the development of accounting master's degrees.

Keywords training; university; critical reading and writing; hyper-modern thought-lifestyle; knowledge; critical thinking

\section{Leitura-escrita e pensamento crítico: desafio da educação contábil}

Resumo Este texto defende a formação para o pensamento crítico que se ancora em um campo de dissertação que vincula a dignidade humana com o desenvolvimento da disciplina contábil. A partir de um trabalho documental e de uma problematização contextual, examina-se como o pensar-viver hipermoderno eliminou o poder da razão crítica como um meio fundamental para promover projetos ético-políticos orientados para o reconhecimento de milhares de seres humanos que na atualidade são excluídos e eliminados por e desde os postulados do modelo neoliberal globalizado. Descreve-se como as contradições socioeconômicas do modelo de desenvolvimento imperante exigem que os programas de Contabilidade Pública repensem seus Projetos Educativos (PE) para decifrar como podem ir ao encontro de seus estudantes e acompanhar em seu processo de formação. Conclui-se que a simples leitura-escrita funcional, alheia ao pensamento crítico, leva à emergência do computatōris globalizzatus que não podem 
LECTOESCRITURA Y PENSAMIENTO CRÍTICO: DESAFÍO DE LA EDUCACIÓN CONTABLE / W. ROJAS / 309

facilmente articular seu saber e suas perícias profissionais às necessidades de sua sociedade. Finaliza-se propondo umas recomendações que facilitem projetar as reformas aos $\mathrm{PE}$ e aos desenvolvimentos dos mestrados em contabilidade.

Palavras-chave Formação; universidade; leituraescrita crítica; pensar-viver hipermoderno; saber; pensamento crítico

Se convive sin problemas con mil misterios irresueltos que nos ocupan diez minutos por la mañana y a continuación se olvidan sin dejarnos escozor ni rastro. Precisamos no ahondar en nada ni quedarnos largo rato en ningún hecho o historia, que se nos desvíe la atención de una cosa a otra y que se nos renueven las desgracias ajenas, como si después de cada una pensáramos: “ya, qué espanto. Y qué más. ¿De qué otros horrores nos hemos librado? Necesitamos sentirnos supervivientes e inmortales a diario, por contraste, así que cuéntennos atrocidades distintas, porque las de ayer ya las hemos gastado". Javier Marías (2013, p. 51)

El peor analfabeto es el analfabeto político. No oye, no habla, ni participa en los acontecimientos políticos. No sabe que el costo de la vida, el precio del pan, del pescado, de la harina, del alquiler, de los zapatos o las medicinas dependen de las decisiones políticas. El analfabeto político es tan burro, que se enorgullece e hincha el pecho diciendo que odia la política. No sabe, el imbécil, que, de su ignorancia política nace la prostituta, el menor abandonado, y el peor de todos los bandidos, que es el político trapacero, granuja, corrupto y servil de las empresas nacionales y multinacionales Bertolt Brecht (1976, citado por López-Sánchez, 2013)

\section{Abordaje del problema}

En el proceso de gestación de este texto, la ocurrencia de una anécdota de aquellas que teje inesperadamente la vida cotidiana, me exhortó a seguir pensando el problema de la formación universitaria y en especial de la contaduría pública. En una ocasión, entré a un restaurante en compañía de un colega, y a los pocos minutos de estar conversando, la dueña se apresuró hacia mí y me dijo: "Yo me imagino que usted es profesor, por lo que le alcanzo a escuchar". Le respondí, un poco sorprendido: "Sí, ¿por qué?”. Ella comenzó a hablarme de la universidad en la que su hijo estudiaba y me pidió que le respondiera una pregunta: “Usted sabe por qué en la universidad a un estudiante le queda tan poco tiempo para poder trabajar a la par que va estudiando?”. Yo sonreí, y sin darme cuenta encontré en esa pregunta un carrefour con mis dudas sobre lo que hace y debe hacer la universidad (la confección de su pénsum de estudio, la instauración de nuevas prácticas pedagógicas y didácticas, las formas de comunicar a la sociedad el deber ser de la universidad y, en especial, los modos de operar en los procesos de formación). El suceso anterior me condujo a prestarle mayor atención al siguiente planteamiento de Boaventura de Sousa-Santos:

La universidad se enfrenta por todos lados a una situación compleja: la sociedad le hace exigencias cada vez mayores, al mismo tiempo que se hacen cada vez más restringidas las políticas de financiamiento de sus actividades por parte del Estado. Doblemente desafiada por la sociedad y por el Estado, la 
universidad no parece preparada para en-

frentar los desafíos, más aún si estos apuntan hacia transformaciones profundas y no hacia reformas parciales (1998, p. 225).

Sin duda, la pregunta que me hizo la dueña del restaurante y el planteo de Sousa sobre el quehacer universitario, intensificaron la necesidad de visibilizar y responderme en voz alta las siguientes preguntas: ¿cómo la universidad transmite a los jóvenes, y por extensión a sus familias, su proyecto académico actual?, ¿'se promueve en los programas académicos una lectoescritura que fortalezca un pensamiento crítico?, ¿los estudiantes están preparados para comprender y problematizar los presupuestos de la racionalidad instrumental-productiva que se ha ido imponiendo a lo largo y ancho del quehacer universitario, y en la mirada con que la sociedad observa los desarrollos de la universidad?

\section{Universidad y nuevas subjetividades: homo globalizzatus}

Hoy estamos ante nuevos procesos de subjetivación (Dufour, 2007a) que han transformado el desarrollo de la vida cotidiana y por tanto, obligan a replanteos de la formación universitaria. Eric Hobsbawm (2000) sostiene que estamos en presencia de un homo globalizzatus emergente de los desarrollos científicos y tecnológicos del siglo XX y del imaginario económico. Vivimos bajo el imperativo de un liberalismo afraternal. Veamos el perspicaz planteo de Hobsbawm:

\begin{abstract}
En el pasado la vida de muchas empresas se basaba en la aceptación general de los valores de solidaridad y en los vínculos familiares. Es aún así, en Italia, en el "milagro" de la pequeña empresa. Y es todavía así en la vivaz y emprendedora diáspora China en el sudeste asiático (...) Hoy, sin embargo, en la era del liberalismo, está tomando cuerpo la idea de que estas antiguas motivaciones no tienen ya ninguna importancia, que pueden ser destruidas sin ninguna consecuencia. Es decir, que se puede gestionar enteramente una economía sin recurrir a ella. La misma lealtad a la empresa, ya sea de sus trabajadores o de sus directivos, ha dejado de valorarse. Se considera perfectamente posible que los éxitos de la empresa convivan con la inseguridad permanente y con el cambio continuo de sus empleados (2000, pp. 157-158).
\end{abstract}

Pensemos por qué le preocupa a la madre que me interrogó el hecho de que su hijo no pueda trabajar mientras avanza en la realización de sus estudios. Su inquietud, aunque surge desde la necesidad económica, puede equipararse a lo que demanda la lógica operante del homo globalizzatus, sin noción de pertenencia, sin continuidad. En este contexto, los estudios universitarios se pueden visibilizar, tal como lo afirma Fernando Cruz-Kronfly (2008) como un proceso acrítico en el cual el estudiante en pocas horas pueda educarse y formarse. Vivimos un pensar-vivir en el que todo lo que se estudia debe arrojar resultados económicos inmediatos. Tal vez el estudio universitario como proceso y acontecimiento extendido es una idea que ha perdido consenso 
social. ¿Será que el estudiante (homo globalizzatus) de contaduría pública se pregunta por el sentido que puede tener esforzarse por aprender críticamente unas teorías, unos conceptos que le pueden problematizar su saber y su realidad sabiendo que en cuanto ponga los pies en la empresa, la lógica que imperará es la de aplicar solo el conocimiento que facilite alcanzar los resultados económicos exigidos por la gerencia y por los empresarios? Si se aceptara que el dominio y la experticia de los saberes profesionales como la contaduría no se alcanzan solo desde las aulas de clase, sino desde las prácticas empresariales - que se viven redefiniendo bajo las reglas del mercado- entonces, vale preguntarse ¿cuál es la utilidad práctica de la formación problematizadora de los saberes?

En la actualidad, participar de un programa de formación universitaria representa una actividad completamente diferente a la experimentada en los siglos XIX y XX en algunos países de Europa, donde la formación estaba orientada a la problematización y creación del conocimiento (Bermejo, 2009). La idea de universidad contemporánea enfrenta una época de cambios vertiginosos que la desafían, pero abogamos por proyectarla y defenderla de los referentes ideológicos que buscan que la universidad beneficie todos los modos y todas las variaciones del mercado (Dufour, 2007a).

Parece entonces que la "autonomía" del ente universitario enfrentada a los recortes de su financiación estatal, a la lógica de la interconectividad, al acceso eficiente de la información y a las motivaciones que guían el neoliberalismo, ha conducido a que los referentes formativos que dignificaban la insti- tución universitaria se vayan evaporando sin tregua.

$$
\begin{aligned}
& \text { La gran novedad del neoliberalismo, en com- } \\
& \text { paración con los sistemas de dominación ante- } \\
& \text { riores, es que aquellos funcionaban mediante } \\
& \text { el control, el fortalecimiento institucional y } \\
& \text { la represión, mientras que el nuevo capitalis- } \\
& \text { mo funciona apelando a la desinstitucionali- } \\
& \text { zación (Dufour, 2007a, p. 217). }
\end{aligned}
$$

El mundo se ha poblado de una multiplicidad de subjetividades acríticas que según Dany-Robert Dufour se caracterizan por estar disponibles para conectarse con todo, un sujeto flotante, indefinidamente abierto a los flujos comerciales y comunicacionales, permanentemente necesitado de mercancías para consumir (2007a, p. 134). Todo indica que ante la emergencia de nuevas subjetividades, las pedagogías que guiaban los procesos de formación de la educación clásica democrática, colisionan (Nussbaum, 2005, p. 320).

Las demandas sociales y políticas que claman por la justicia, por el cuidado del medio ambiente $^{1}$ y por la defensa de la dignidad humana exigen que desde la universidad se cultive un proceso de formación emancipatorio de la lógica que domina nuestro presente. En el contexto de nuestra disciplina, vale adelantar una idea que se ampliará luego: las perspectivas de la educación profesional en contaduría pública en Colombia son cada vez más complejas, si reconocemos que la formación contable se moldea según las demandas de un capitalismo

1 Para pensar la importancia del replanteo entre administración y medio ambiente, Olivier Boiral (2009). 
líquido ${ }^{2}$, el cual potencia la educación de fuerte cuño profesionalista (Gómez, 2010, p. 150). Esta orientación se contrapone a la promoción de teorías contables interpretativas y críticas que defienden la necesidad de establecer distinciones entre las pedagogías que se utilizan para presentar el propio quehacer-instrumental (necesario para un buen ejercicio profesional) y las pedagogías que se deben implementar para la formación crítica que confiere dignidad a la educación liberalis antes referenciada.

\section{Universidad y autonomía formativa}

El devenir de la universidad es tan importante hoy, que pensadores como Jacques Derrida (1997, 2002) y Boaventura de Sousa-Santos (1998 y 2004) lo han trabajado sistemáticamente. Veamos una amplia tesis de Jacques Derrida (1997) que alimenta la disertación:

\begin{abstract}
Ni en su forma medieval ni en su forma moderna ha dispuesto la Universidad de su autonomía absoluta y de las condiciones rigurosas de su unidad. Durante más de ocho siglos, "universidad” habrá sido el nombre dado por nuestra sociedad a una especie de cuerpo suplementario que ha querido a la vez proyectar fuera de sí misma y conservar celosamente en sí misma, emancipar y controlar. Por ambas razones, se supone que la Universidad representa la sociedad. Y, en cierto modo, también lo ha hecho, ha
\end{abstract}

2 La categoría "capitalismo líquido" la propone el sociólogo Zygmunt Bauman (2000) para pensar las transformaciones sociales propias de la modernidad del siglo XX. reproducido su escenografía, sus metas, sus conflictos, sus contradicciones, su juego y sus diferencias y, así mismo, el deseo de concentración orgánica en un solo cuerpo (...) El tiempo de la reflexión, aquí, no significa solo que el ritmo interno del dispositivo universitario es relativamente independiente del tiempo social y reduce la urgencia de la entrega, le asegura una libertad de juego grande y valiosa. Un lugar vacío para la oportunidad (...) El tiempo de la reflexión es, así mismo, la oportunidad de una vuelta sobre las condiciones mismas de la reflexión, en todos los sentidos del término, como si con ayuda de un nuevo aparato óptico se pudiera por fin ver la vista, no solo del paisaje natural, la ciudad, el puente y el abismo, sino también "telecopar" la vista (...) el tiempo de la reflexión es también otro tiempo, heterogéneo con respecto a aquello que refleja y proporciona, quizá el tiempo de lo que llama a y se llama el pensamiento. Es la oportunidad de un acontecimiento del que no se sabe si, presentándose en la universidad, pertenece a la historia de la universidad (pp. 18-19).

Es evidente que para Derrida (1997), la universidad nunca ha mantenido una autonomía absoluta, ni una unidad de visiones para ver y pensar el mundo. Así, puede aceptarse que la universidad se ha caracterizado por pensar y construir artefactos para el presente y el futuro de las sociedades desde su pretendida creencia en el buen uso de la razón. Esta posición filosófica de la universidad se refuerza con la siguiente postura de Sousa cuando sostiene que "la universidad es tal vez la única institución en 
las sociedades contemporáneas que puede pensar hasta las raíces en las razones por las cuales no puede actuar de conformidad con su pensamiento" (1998, p. 273). Esto significa que la universidad aún en nuestros tiempos hipermodernos no puede renunciar al privilegiado uso del libre raciocinio y, por tanto, al autoexamen crítico con que se le reconoce su misión social. Favorecer el pensamiento crítico no arriesga su existencia; por el contrario, eleva a su máxima expresión su pertinencia social.

En este sentido, resulta significativo resguardar la idea de Universidad de Cristovam Buarque destacada por De Sousa: "la política de la universidad debe combinar el máximo de calidad académica con el máximo de compromiso social (...) Lo que caracterizará el producto, por lo tanto, es su calidad, su condición de élite, pero lo que caracterizará su uso es su amplio compromiso - su condición antielitista-" (1998, p. 253).

Ante los desafíos que impone la hipermodernidad $^{3}$, resulta fundamental mantener la idea de universidad como organización cultivadora del pensamiento crítico que alimenta la formación científica y profesional bajo el marco de la justicia y el bienestar social. En esa dirección, se cree que las pedagogías universitarias pueden verse como dispositivos que proporcionan múltiples referentes teóricos que conectan las profesiones y las ciencias, con los problemas que violan y trasgreden los valores que sostuvie-

3 Se sabe que en la actualidad, hay un debate sobre los conceptos de posmodernidad, hipermodernidad, modernidad tardía, para caracterizar el pensar vivir contemporáneo, pero, no es del caso entrar en esta discusión aquí y en tal razón, estos conceptos se toman como sinónimos a lo largo del texto. ron el proyecto de dignidad humana moderna. Se cree que a pesar de todas las limitaciones económicas y administrativas que ha enfrentado la universidad colombiana, en ella hay un cuerpo académico capaz de mejorar los proyectos educativos de los programas que se ofrecen.

Desde la sociología, el psicoanálisis, la filosofía, la pedagogía y la economía política crítica, se ha podido visualizar cómo el fin de la formación universitaria no puede regirse bajo los fines maximalistas de un empresariado que cada vez se apodera más del gobierno de los pueblos. La diversidad y heterogeneidad de las comunidades universitarias han consensuado que la formación puede desplegarse bajo pedagogías centradas en facilitar la comprensión entre lo que funciona y lo que no funciona, entre lo que se hace y lo que no se hace, entre lo que es y lo que podría ser. Por lo anterior, se considera que los resultados y los logros en la universidad no deben pensarse ni medirse bajo los criterios de la eficiencia y la productividad de la empresa (De Sousa, 2004, p. 4). La misión de la pedagogía universitaria es "abrir la mente" para el pensamiento y el sentimiento de la vida, y esa finalidad en sí misma requiere una libertad universitaria que Derrida (2002) denomina "incondicional de cuestionamiento y de proposición" (p. 10).

Se puede admitir que históricamente la universidad en su esencia formativa e investigativa se ha ubicado por diversos objetivos y decisiones académicas, en una especie de foco identificador y estudioso de los grandes problemas con que han tropezado las sociedades modernas. A pesar de la imposibilidad real que tiene la universidad para "congelar" la lógica dominante del mundo, puede sostenerse que la formación 
del pregrado como mínimo debe mantener espacios universitarios "huecos" entre las asignaturas para que los estudiantes tengan la posibilidad de experimentar reflexivamente cómo los saberes que se están apropiando les permiten pensar, entre otras cosas, las consecuencias globales y locales del actual modelo económico que ha separado lo económico y lo social (Bauman \& Donskis, 2015, p. 105; Boltanski \& Chiapello, 2002). Insistimos, la formación universitaria que centra sus proyectos en el desarrollo del pensamiento crítico nunca ha girado a la velocidad de los procesos reales con los que evoluciona la civilización técnica instrumental (Gadamer, 1996).

Como organización productora de conocimiento, la universidad contemporánea reafirma su misión social; de no hacerlo, castraría al estudiante de un proceso de reflexión y sensibilización que le facilite asumir una actitud indagadora sobre los principales límites y anomalías tanto de su disciplina como del sistema mundo en el que vive. Como lo sostiene Derrida: "la universidad debería, (...) ser también el lugar en el que nada está a resguardo de ser cuestionado, ni siquiera la figura actual y determinada de la democracia; ni siquiera tampoco la idea tradicional de crítica" (2002, p. 14). Un estudiante universitario formado solo en el marco conceptual de las técnicas y las tecnologías que soportan su campo profesional (en este caso, la contaduría pública) difícilmente podrá identificar que el hombre, como lo dice Ana Berezin, "es el ser que puede saber lo que no puede saber, el que es capaz de enfrentarse a lo que no es capaz de afrontar" (2010, p. 25). El dispositivo formativo de un programa de estudio no opera legítimamente si no logra suscitar en sus estudiantes y sus profesores un sentimiento y una racionalidad sospechosas de la realidad imperante de su tiempo. No exhortar a lo anterior implica justificar que la universidad se aleje de su misión expresiva de porvenires, de esperanzas y resistencias; en esta perspectiva, que no es nueva en ningún sentido, se pretende pensar que la educación universitaria no puede ser vista como un medio efectivo para garantizar la lógica productiva-instrumental afraternal, que poco a poco se va imponiendo en la lógica cotidiana (Rojas, 2002).

\section{La universidad: espíritu crítico en la sociedad}

Ser universitario, al menos, desde el lugar de partida de este trabajo y en el campo disciplinar que nos ocupa, implica formarse para comprender que crear una verdad (aunque imaginaria) puede hacer morir y emerger una parte de las representaciones y los valores que guían un pensar-vivir determinado.

Como espacio privilegiado para pensar críticamente el hombre, la sociedad y la ciencia (Borrero, 2008), la universidad puede contribuir a la democratización de una sociedad al proponerse unos procesos pedagógicos que cultiven la lectoescritura crítica como una "caja de herramientas" fundamental para construir un pensamiento crítico, para disentir sobre los referentes con que opera la globalización, por ejemplo, la desimbolización del dinero que, según Dufour, ha llevado a un tipo de despolitización y de desideologización de los referentes culturales con que los sujetos modernos hicie- 
ron fuertes sus ideas de comunidad (2007a, pp. 221-224). Además de aspirar a una formación sólida y estructurada desde el punto de vista profesional, el estudiante universitario requiere amigos del pensamiento que puedan potenciar el diálogo sobre los problemas, las vivencias individuales y las diversas "verdades" que le encarcelan momentáneamente al mundo que los contiene. Dicho en otras palabras, la universidad como una organización destinada a los procesos de formación, no debería considerarse como un mero centro de educación propiciadora de destrezas y competencias instrumentales, sino también de teorías, conceptos y valores que faciliten la desmitificación de los valores y los miedos que configuran la cultura "hipermoderna" (Bauman \& Donskis, 2015; Lipovetsky, 2008).

La educación profesionalizante carente de pedagogías que den relevancia a procesos de lectoescritura crítica contribuye al crecimiento de profesionales infraeducados no aptos para la actividad investigativa y la proyección social.

\section{Ser universitario exige superar la lectoescritura funcional}

La estructuración de los programas en la universidad colombiana ${ }^{4}$ debe volver a repensar las

4 Es importante traer a colación a William González (2012), quien considera que en Colombia, a partir de la Ley 1286 de 2009 y el Conpes 3582 de 2009, Colciencias nos reintroduce al metarrelato capitalista. Este es un apartado de su argumentación: "de la misma manera que la época de la Ilustración creyó alcanzar la emancipación de la violencia a través de la razón, este nuevo metarrelato quiere hacernos creer que podemos emanciparnos de la pobreza a través del desarrollo tecno-industrial y comercial, pero a diferencia de la época de la Ilustración aquí ya no nos pre- pedagogías en relación con la lectura y escritura crítica, para que los estudiantes puedan, si así lo desean, relacionarse reflexivamente, tanto con el saber que se apropian, como con las lógicas del poder que imperan en su tiempo. Para propiciar la lectoescritura crítica se requiere que la universidad fomente en los estudiantes la aprehensión de su saber (problemas, teorías, conceptos y técnicas) bajo ambientes dialógicos en los que se privilegie la necesidad de contextualizar desde distintas ópticas los temas a tratar, la expresión de los puntos de vista individuales (emocionalidades, placeres y dificultades para relacionarse con el tema) y las reflexiones puntuales sobre el quehacer disciplinar; en los programas de contaduría pública, estos criterios reclaman atención. Fomentar la lectoescritura implica, entonces, hacer que el estudiante identifique que el aula, el profesor y sus compañeros conforman un mundo abierto para el intercambio, la discusión y los consensos. Lo anterior facilita que el estudiante reconozca, valore y respete las tradiciones académicas que han situado y enriquecido su disciplina y su cultura. Dicho de otro modo, la lectoescritura y el pensamiento crítico se vigorizan desde las aulas de clase (o cualquier otro espacio formativo), si se logra que los estudiantes puedan entender los intereses cognoscitivos y los grandes obstáculos con los que han jugado y juegan las comunidades científicas y los gremios relacionados con su disciplina. Es fundamental, siguiendo a Daniel Cassany, que todo programa permita que el estudiante se haga "consciente de que puede entender un

guntamos si lo que producimos como conocimiento e investigación «es verdad»; sino que preguntamos «¿para qué sirve?» y sobre todo: «¿se puede vender?»" (p. 13). 
texto sin creérselo, discutiendo el contenido o el punto de vista del texto y manteniendo otras posturas ideológicas" (2011, p. 34). De esta forma, la lectoescritura crítica se concibe como un medio disparador de entendimientos, redesciframientos y reconfiguraciones tanto sentimentales como racionales.

La lectoescritura crítica permite que el estudiante pueda darse cuenta y exteriorizar que todos los libros, que todos los artículos llevan discursos que se amparan en ideologías y representaciones que buscan describir y recrear una determinada realidad. El proyecto de formar ética y estéticamente un profesional virtuoso, ayer y hoy, ha exigido que el estudiante tenga la competencia para conocer cómo en un texto se expresan diversos recursos lingüísticos tales como: selección léxica, énfasis u ocultación, intensificadores, etc. (Cassany, 2011).

Debemos reconocer que educar en la lectoescritura funcional (Cruz, 1998, p. 57) lleva a que los estudiantes no pongan en tela de juicio la racionalidad productiva-instrumental que dirige su pensar-vivir, a la que le convienen las mentes fugaces y hedonistas; se expulsa así la finalidad cognoscitiva y reflexiva que prevaleció desde la antigüedad hasta el espíritu que caracterizó el mundo universitario moderno. Renunciar a la lectoescritura funcional implica defender la continuidad de lo que ha significado la universidad contemporánea con la tradición letrada que prohijó el respeto, la solidaridad y la fraternidad respecto del otro y de la vida. La lectoescritura funcional atrapa al sujeto en los eufemismos con que se tejen los discursos "progresistas" que poco a poco han ido acabando con los derechos humanos.
Ahora bien, no se debe olvidar que el ejercicio de la lectoescritura y del pensamiento crítico tiene un costo existencial que hay que saber asumir. La filosofía occidental nacida en Grecia planteó desde los relatos trágicos cómo la vida de los seres humanos se estremece cuando se entera de que no necesariamente todos los procesos en esta vida avanzan siempre de manera progresiva. Vale la pena retomar con ahínco la siguiente sentencia de Fernando Cruz-Kronfly:

\begin{abstract}
La condición trágica de la existencia humana rompe no solo con la mítica del progreso sino con la tesis de una involución sostenida, rumbo al apocalipsis. Ni progreso ni apocalipsis, sino ambigüedad permanente, ambivalencia y conflicto constantes, fragmentación esencial del sujeto, lucha siempre renovada entre el bien y el mal, conflicto insuperable entre naturaleza y cultura, eterno retorno a lo mismo travestido según el tono de las diferentes épocas (2003, p. 52).
\end{abstract}

Hay esperanzas humanas que nacen y emergen del pensamiento que se autocritica ambivalentemente y que no teme el desafío de la búsqueda, de la incertidumbre.

En efecto, la formación lúcida permite, primero, comprender las diferentes explicaciones críticas frente a los ideales modernos que consideraron posible la construcción de un mundo plenamente feliz; y segundo, posibilita ver la alegría que aparece cuando se identifica que la vida inmediata, como dice Jean Ladrière (1977), “...está inmersa en la particularidad de los intereses contingentes, está llena de imágenes falaces, no es capaz de comprenderse a sí 
misma y desconoce su propio sentido; en una palabra, se caracteriza por el error" (p. 25). La lectoescritura crítica es uno de los principales medios que la cultura occidental ha construido para descifrar sin temores traumáticos el mundo y las complejidades del ser humano.

No debe olvidarse el poder de la lectoescritura crítica para consolidar la formación de profesionales capaces de proyectar, por ejemplo, la investigación connivente y de ruptura que va más allá de lo institucional y que, por tanto, puede resultar fundamental para la aparición de nuevos valores y prácticas sociales (González, 2012, p. 18). Dicho de otro modo, bajo la promoción de la lectoescritura y el pensamiento crítico, la universidad contribuye a la emergencia de perspectivas de análisis, no solo a favor de las profesiones y las ciencias, sino de los valores y las ideologías que se anteponen a las prácticas sociales excluyentes, indignantes y colonizadoras.

No se va, ni se está en la universidad para consumir sin rumiar críticamente la tradición y los supuestos teóricos de los saberes. En la medida en que la formación superior prepara para la lectoescritura lúcida, el universitario aprehende cómo puede entender y defender los grandes ideales de la cultura y la ciencia. Se sabe, por ejemplo, que el ser humano puede hacer de la razón ilustrada y de las artes medios necios a la promoción de justicia y vida igualitaria (Steiner, 1992). Es cierto, las humanidades y el arte por sí mismos no impiden la negación de la dignidad humana, pero también es cierto que la lectoescritura asumida posibilita razonar y, como lo afirma Ana Berezin: "también hay crueldad (y no casualmente, ya que hay una íntima relación) en los planes económico-políticos que con frías cifras hacen crecer los hambrientos y excluidos en una lenta tortura de por vida" (2010, p. 27). Leer y escribir son los medios que los valerosos miembros de la universidad deben apropiarse para materializar el ethos filosófico que Francisco Javier de la Higuera (2007) resalta de Michel Foucault: "crítica permanente de nuestro ser histórico"... "crítica de lo que decimos, pensamos y hacemos" (p. lvi).

Las pedagogías que valoran la lectoescritura y el pensamiento crítico preparan al estudiante universitario para que evalúe y elija entre las múltiples formas que tiene, para que no quede atrapado en el círculo de las contradicciones de su sociedad. Un sujeto que no sienta "desgarrarse" del pensar-vivir posmoderno en su proceso de formación, no podrá entender las limitaciones y el peligro de la lectoescritura funcional.

En efecto, identificar las formas de argumentación que imperan en los contenidos temáticos, develar los mecanismos mediante los cuales se legitiman "verdades" y se doblega a los individuos para obedecer las disposiciones de quienes detentan el poder, allana el camino al estudiante para no dejar que su mente sea colonizada; leer críticamente es elegir textos que sean enriquecedores para problematizar lo que supuestamente no es discutible o se da por sentado; es leer la realidad y las propias experiencias desde el reto de la transformación para un bienestar incluyente, común; escribir críticamente es no limitarse a dar cuenta de lo leído como resultado del requisito académico, es cuestionar lo que merezca cuestionamiento, es proponer, es pronunciarse. 


\section{8}

Por ejemplo, analizar a través de las lecturas algunos de los referentes con que opera la globalización es acercarse a la comprensión de lo que ha sido transformado en nombre de un supuesto "beneficio común", tal como se puede evidenciar en las tesis de Dufour cuando habla de la desimbolización del dinero (2007a, pp. 221-224).

\section{Por una recontextualización crítica de la formación contable}

La educación contable hoy es una preocupación tanto para los Estados, como para las instituciones y las comunidades académicas que internacional y nacionalmente buscan responder a las exigencias de la globalización. Proponer y liderar los desarrollos en este tema implica reconocer que en él hay distintos intereses e ideologías que se ponen en contradicción y colisión. Por un lado, están los que promueven la globalización como un proyecto enteramente positivo para todas las sociedades, y por otro, quienes lo advierten como un fenómeno que exige cuidados frente a los valores y las políticas locales que definen lazos comunales e identidades.

Veamos lo que advierte Jorge Manuel Gil (2004), a los estudiantes latinoamericanos, al respecto:

...estamos asistiendo a una etapa formidable de la historia de la humanidad, del conocimiento universal. [...] América Latina no puede alentar la espera pasiva de la globalización ni contentarse con la adaptación acrítica. La universidad latinoamericana no puede (en realidad, no debiera) aceptar el modelo unidimensional de la contabilidad normativa ni el esquema casuístico de la administración. [...] Corremos el peligro de transformar nuestro conocimiento en una externalidad de la globalización, sin base científica, sin adecuación a nuestras realidades, sin pruebas empíricas de eficiencia, sin participación activa en la creación de nuestras normas, sin ser artífices de nuestro propio destino. Estamos tropezando nuevamente con la misma piedra. Está cayendo sobre nosotros la maldición del malinche y estamos actuando como los lenguaraces mapuches (pp. 42-43).

Más allá de los distanciamientos ideológicos que se tejen sobre los alcances y las consecuencias de la globalización para América Latina - y, específicamente, para Colombia-, en este acápite se desea presentar unas ideas que no agotan el tema pero que contribuyen al pensamiento de la educación contable, para promover una discusión y un consenso sobre la importancia que debería tener la lectoescritura crítica en los programas de estudio de contaduría pública.

Las facultades y/o programas de contaduría pública que en la actualidad enfrentan procesos de reforma curricular o que están definiendo sus proyectos educativos, no deberían soslayar la necesidad de repensarlos, como un gran primer paso; participar y promover la redefinición del quehacer universitario contemporáneo para identificar cómo la globalización y la economía neoliberal no solo han minado los presupuestos de la educación de un saber, de una profesión, sino los principios y valores desde los cuales 
se dignificaban la vida y los seres humanos en toda la civilización occidental.

Pretender reformular la educación contable, desde una idea de contabilidad en la que no se contextualizan las necesidades y los prejuicios que hay sobre esta disciplina (Grajales, 2007) y sobre su ejercicio profesional (Cuevas, Grajales \& Usme, 2013) o desde una de las exigencias jurídicas actuales, como la de la convergencia con los International Financial Reporting Standard (IFRS), puede conducir a trabajos afásicos que solo responderían al mercado y a las exigencias de ley. Una postura acrítica desatiende los desafíos que tiene la educación contable como el de contribuir a la identificación de las consecuencias de ciertas ideologías económicas y prácticas empresariales que atentan contra el pensamiento igualitario y libertario de las sociedades contemporáneas. Divorciar el replanteamiento de la contabilidad de las discusiones y proyecciones interdisciplinarias que puede hacer la universidad, implicaría desconocer que en la posmodernidad hay unos nuevos presupuestos, nuevas "certezas" y grandes conflictos sociales que desafían tanto su existencia como su legitimidad social.

En la refundación de los proyectos educativos de contaduría, convendría fortalecer las discusiones y las alianzas interdisciplinarias con quienes defienden la universidad como facultad de juicio crítico de la sociedad (González, 2012, p. 9). Potenciar la educación contable requiere arrogarse la posibilidad de enfrentar los imaginarios que facilitan creer que el juicio profesional equitativo en contabilidad se puede formar desde prácticas pedagógicas centradas en el mundo del trabajo (Rueda, 2013).

No tenemos dudas sobre que los currículos de Contaduría Pública deben incorporar algunos de los principales referentes que guían los IFRS, pero circunscribirse pasivamente a ellos implica mantener ciertos supuestos que han reducido peligrosamente el accionar y los propósitos académicos e investigativos de la disciplina contable. En particular, preguntémonos, por una parte, si desde la incorporación de los IFRS en Colombia: a) ¿se ha resuelto la visión y la representación reificada del ser humano en el trabajo?; b) ¿han cambiado las valoraciones que la empresa puede hacer de la ecología?; c) ¿cómo enseñar técnicas contables desde un marco conceptual que nubla los problemas y las críticas que se hacen desde la teoría contable? y por otra, ¿bastaría plegarse a las IFRS para entender cómo y desde dónde grandes empresas multinacionales se han caído como castillos de naipes? Quienes incorporan las IFRS no pueden desconocer que la educación contable, como lo señala Salvador Carmona haciendo referencia a la investigación de Nihel Chabrak y Russell Craig (2013), debe ir más allá de su dimensión técnica para avanzar en su involucramiento con el mundo social. A propósito de lo anterior, aplicar los IFRS no puede reducirse a la adaptación acrítica y consentida que no discute ampliamente las visiones reduccionistas, las cuales desconocen que el discurso contable puede vincularse en cualquier momento con las ideologías que imperan en una organización (Archel, 2007). Enseñar la contabilidad en la educación superior exige, como mínimo, reconocer que hoy 
no se puede hablar impasiblemente de estudiantes de contabilidad ni de profesión contable, pues en algunos países como España hasta muy poco aparecen los pregrados en contabilidad y la auditoría no goza de la condición de "profesión" (Carmona, 2013).

Paralelo a la adopción del replanteamiento de un proyecto educativo en contabilidad, corresponde pensar cómo y desde dónde enfrentar los imaginarios y las nuevas subjetividades con que llegan los estudiantes. Se requiere comprender que los intereses de los nuevos estudiantes y la desfinanciación de la universidad no deberían afectar el ethos universitario; se sabe desde los planteamientos de Ken McPhail (2002) que la educación contable noble colisiona con lo afraternal que impera en el capitalismo de mercado. Hoy, debería reconocerse que definir y consensuar un proyecto de formación en contaduría pública en Colombia que desconozca y no problematice los valores que tejen el pensar vivir de nuestros tiempos, resulta inadmisible. Insistimos, un proyecto educativo que no dialogue y no implique a los departamentos y/o facultades comprometidos con el estudio de lo que Rafael Carvajal-Baeza (2008) señala como los nuevos avatares y las desventuras de la razón, impide que sus egresados puedan salir de los mandatos azarosos del ultraliberalismo y del hedonismo consumista.

Dadas las ideas hasta ahora presentadas, puede expresarse que el pensar y proyectar la educación contable es y será siempre una tarea compleja y retadora para la comunidad académica; especialmente hoy, cuando se puede aceptar que la gran mayoría de los estudiantes y los profesores ${ }^{5}$ se mueve en un mundo líquido que ha promovido la no culpabilización y el alejamiento del pensamiento crítico (Dufour, 2007a, p. 230).

Repensar la educación contable es un trabajo que expresa y exige relacionamiento de los saberes que facilitan comprender no solo las tramas de la contabilidad (Ospina, 2006) sino los obstáculos y los intereses que existen en la comunidad académica para defender y proyectar el desarrollo social y científico de la profesión contable. Se puede reconocer que hay distintas perspectivas de comprensión y problematización sobre el quehacer profesional: corriente principal, corriente interpretativa, corriente crítica (Chua, 2009), pero ello no garantiza que desde el estudio de estas corrientes se proponga un tipo de formación integral que prohíje una lectoescritura crítica en contaduría pública. Por ejemplo, se sabe que la comunidad contable no ha definido cómo superar la tradición legalista en los procesos de formación universitaria que en Colombia, y quizás en varios países de Latinoamérica, a juicio de Mauricio GómezVillegas y Carlos Mario Ospina (2009) "ha implicado una especie de rezago en la difusión, evaluación, contrastación y construcción de concepciones académicas de la contabilidad..." (p. 13).

Se sabe que hoy se ha propuesto estudiar las Normas Internacionales de Formación para Contadores Profesionales (International Education Standards, IES) (IFAC, 2008); pero ellas no precisan, por ejemplo, las características

5 Para enriquecer la descripción del "rol" que ha jugado el profesor en el estado actual de la universidad, Zygmunt Bauman y Leonidas Donkins (2015, p. 176). 
económicas y sociales que influyen directamente en la percepción que tienen los estudiantes sobre la relación que debería existir entre la contabilidad y la sociedad; las expectativas profesionales de los jóvenes universitarios que llegan a cada uno de los programas de contaduría; ni mucho menos asumen cuáles son los problemas relacionados con la lectoescritura que potencian y obstaculizan el desarrollo del conocimiento. Dicho de otra manera, las normas se presentan como un instrumento despolitizado (Pesqueux, 2010) que configura territorios transnacionales que desconocen los problemas y las asunciones del pensar-vivir contemporáneo. Se cree que la educación contable puede salir al encuentro de los estudiantes (homo globalizzatus), abrirles la puerta y acompañarlos de tal forma que ellos puedan ver y comprender cómo la lectoescritura crítica no es un anacronismo inútil sino un recurso que potencia la dignificación del pensamiento y de la vida.

Puede reconocerse que en España (Carmona, 2013) y Colombia hay en general una desconexión pedagógica entre contabilidad y sociedad; empero, tal fenómeno puede empezar a tener mayores atenciones si contribuimos a pensar contextualmente cómo el pensar-vivir de nuestros tiempos y los grandes problemas económico-sociales del neoliberalismo exigen que la comunidad académica en contabilidad, promueva la lectoescritura crítica como un medio de materializar la dimensión social de la profesión.

Insistimos, el problema de la lectoescritura funcional en contabilidad no se puede invisibilizar bajo los modelos que se proponen y se implementan para la autoevaluación de calidad de los programas académicos en Colombia.
Fomentar la lectoescritura crítica como medio que facilita la autonomía del pensamiento y la independencia mental, implica aceptar que es necesario repensar los supuestos de la educación que impiden ver con lucidez los intereses y las limitantes, que por una u otra razón han estructurado el ejercicio de la docencia en Colombia.

Puesto que algunas ideas señaladas anteriormente, pueden ser entendidas como "apocalípticas", digamos que no se desconoce que la lectura y la escritura crítica ejercida por algunos gremios y algunas comunidades académicas en Colombia (Cubides, Maldonado, Machado, Visbal \& Gracia, 1999; Gracia, 1998; Visbal, 1999), han facilitado pensar la contabilidad como un campo del conocimiento autónomo, capaz, primero, de elaborar teorías y métodos de valoración y aseguramiento de la calidad de la información, y segundo, de descentrarse de las tensiones y las tramas con que se ha buscado ceñir el ejercicio de la profesión contable a los cálculos y auditorías rentistas, hijos putativos del mito del progreso económico. La lectura y la escritura crítica han sido determinantes para la identificación, no solo de distinciones entre los campos de acción del profesional contable sino también para precisar la contradicción contable "Europeo-Americana" (Gracia, 2010).

\section{Maestrías en contabilidad, un desafío en el replanteamiento de lectoescritura crítica}

En la actualidad, en Colombia, por ejemplo, la aparición de programas de maestría en conta- 
bilidad exige pensar la orientación pedagógica que se le está dando a la lectoescritura crítica como medio que, específicamente, facilita el estudio y el desarrollo de los trabajos de grado (monografías).

Dicho de otro modo, los objetivos investigativos que dan vida a las maestrías en contabilidad obligan a pensar si con la lectura funcionalista como centro de la pedagogía en los pregrados, se facilita el análisis que exige la problematización y el desarrollo del conocimiento contable. Para nadie es un secreto que una maestría en su concepción clásica, ya sea profesional o investigativa, se justifica por el análisis crítico que se presenta en el trabajo de grado. Una maestría en contabilidad requiere pedagogías que fomenten la lectoescritura crítica de las prácticas que han podido y pueden adocenar a los contadores públicos en las nuevas formas de alienación que están detrás del ultraliberalismo que ha divinizado el mercado (Dufour, 2007b).

$\mathrm{Si}$ a los profesionales de la contabilidad no se les forma en la comprensión de lo que significa producir conocimiento universalmente nuevo, es decir, que agregue algo al saber y/o que se cuestione el statu quo del paradigma dominante (Cruz, 2010, p. 16), el futuro de las maestrías en contabilidad será incierto, mientras estas no tengan la demanda que haga posible la investigación crítica e interpretativa que tanto requiere la sociedad. No visualizar los proyectos de desarrollo académico conduce, por ejemplo, a que el asunto de la producción del conocimiento contable institucional no facilite procesos de deconstrucción de los enfoques regulativos convencionales que obstaculizan el pensamien- to en libertad. Formar implica ofrecer al futuro profesional de la contabilidad un instrumental para pensar libre y autónomamente los imaginarios y valores que promueven la emergencia del computatōris globalizzatus que no puede articular su saber y sus experticias profesionales a las necesidades de su sociedad.

\section{Epílogo}

Uno de los requerimientos de mayor urgencia en la universidad contemporánea es repensar la práctica pedagógica que se utiliza y se privilegia para divulgar los fundamentos y el contexto en el que ha operado y debería operar el profesional de la contabilidad; el rechazo a una lectura funcional significa que la comunidad académica entiende que el estudiante debe formarse para leer y reescribir con sentido crítico sus propias experiencias y, por supuesto, proyectarlas bajo el deseo libertario e igualitario que procura la actitud creativa y revolucionaria. La universidad colombiana está llamada a garantizar que sus estudiantes evalúen las demandas que impone un entorno global y que ponen en peligro la conexión entre las identidades diferentes y desiguales que pueblan su espacio (García-Canclini, 2008), así como la posibilidad de mantener vigente el proyecto de la dignidad humana. Una de las tareas que urgen en la actualidad es que la universidad - en especial, los programas de Contaduría-conecte su dimensión académica con los valores modernos de justicia y bienestar social; de lo contrario, sus miembros se verán cada vez más abocados a ser unos convidados de piedra para cuestionar el sentido alucinatorio de la utopía progresista moderna. 
Cuando se plantean las anteriores conjeturas sobre el sentido de la universidad y en especial sobre la formación contable, me he plegado a la siguiente tesis de Alain Finkielkraut (1999): "Si el hombre afrontara con franqueza la melancolía de su condición, sabría que el sentimiento no elimina la distancia entre los seres, sino que la ahonda" (p. 39). Es necesario que las universidades en la actualidad faciliten que sus miembros se formen para otear el sinsentido de una vida profesional desresponsabilizada del examen crítico de la existencia humana. El sentido más sublime de la formación universitaria es hacer que el otro y la vida misma puedan por fin ser leídos más allá de las informaciones que reclaman y animan a mirarlos funcionalmente. El punto de vista que subyace a este planteamiento no resulta de un sentimiento de escepticismo per se frente a los poderes-saberes que han apostado por la reificación del mundo y de los seres humanos, sino de aceptar la siguiente tesis de Rafael Campo (2006):

Ciertamente, hoy, hay más saber que antes, en el mundo en general (...) pero todo este aumento en la capacidad productiva y en el saber no ha redundado lo esperado en la solución de problemas humanos básicos y esenciales, como el problema de la convivencia y el de la relación con el medio ambiente, que tanto preocupan actualmente. Una búsqueda de respuesta a por qué ese incremento impresionante de la capacidad de destrucción, de comprensión de las leyes de la naturaleza y de la historia, no han ayudado suficientemente a resolver los problemas, tiene qué ver con que todavía no se entiende bien, sobre todo por los educadores, lo que significan el valor formativo del conocimiento y la información (2006, Prólogo, p. xiii).

Finalmente, retomando los razonamientos de Javier Marías (2013) y Bertolt Brecht (1976), citado por Rogelio López-Sanchez (2013) que se presentan en el encabezado de este texto, digamos que el profesional educado en lectoescrituras funcionales queda capturado en el analfabetismo político que lo hace presa fácil del pensar light que representa la vida como un espacio afraternal y sin mayores problemas, y en el que la atrocidad del sufrimiento humano contemporáneo alimenta la banalidad de su juicio moral contra los granujas, los corruptos y los serviles, de quienes, de una u otra forma, ignoran la destrucción del planeta y los miles de seres humanos que son desechados de la lógica productiva actual.

\section{Referencias}

Archel, Pablo (2007). Discurso contable, ideología e informes anuales: un enfoque interpretativo. Contaduría, Universidad de Antioquia, 51, 41-64. Disponible en: https:// aprendeenlinea.udea.edu.co/revistas/index. php/cont/article/viewFile/2147/1749

Bauman, Zygmunt (2000). La modernidad líquida. Buenos Aires: Fondo de Cultura Económica, FCE.

Bauman, Zygmunt \& Donskis, Leonidas (2015). Ceguera moral. La pérdida de sensibilidad en la modernidad líquida. Madrid: Paidós.

Berezin, Ana (2010). Sobre la crueldad. La oscuridad en los ojos. Buenos Aires: Psicolibro. 
Bermejo-Barrera, José Carlos (2009). La fábrica de la ignorancia. La universidad del 'como si'. Madrid: Akal.

Boiral, Olivier (2009). El medio ambiente en la administración y la administración medio ambiental: lo que está en juego y las perspectivas de futuro. En Omar Aktouf. La administración: entre tradición y renovación, 481-513. Cali: Universidad del Valle, Universidad Libre, Artes Gráficas de Valle.

Boltanski, Luc \& Chiapello, Ève (2002). El nuevo espíritu del capitalismo. Madrid: Akal.

Borrero-Cabal, Alfonso, S.J. (2008). La universidad. Estudios sobre sus orígenes, dinámicas y tendencias: organización universitaria. Bogotá: Pontificia Universidad Javeriana.

Brecht, Bertolt (1976). Escritos políticos. Buenos Aires: Futura.

Buarque, Cristovam (1986). Uma ideia de universidade. Brasília: Editora Universidade de Brasília.

Campo, Rafael (2006). Prólogo. En John Cardona-Arteaga \& Miguel Ángel ZapataMonsalve. Educación contable: antecedente, actualidad y prospectiva (p. ix-xix). Medellín, Colombia: Universidad de Antioquia.

Carmona, Salvador (2013). Accounting Curriculum Reform? The Devil is in the Detail. Critical Perspectives on Accounting, 24 (2), 113-119.

Carvajal-Baeza, Rafael (2008). Doctorados en administración de empresas. ¿Anda por ahí el homo sapiens? En Rafael Carvajal-Baeza (ed.). Gestión crítica alternativa, 207-248. Cali: Facultad de Ciencias de la Administración, Universidad del Valle.
Chabrak, Nihel \& Craig, Russell (2013). Student Imaginings, Cognitive Dissonance and Critical Thinking. Critical Perspectives on Accounting, 24 (2), 91-104.

Cassany, Daniel (2011). Prácticas lectoras democratizadoras. Textos de Didáctica de la Lengua y la Literatura, 58, 29-40.

Chua, Wai Fong (1986-2009). Desarrollos radicales en el pensamiento contable. En Mauricio Gómez-Villegas \& Carlos Mario Ospina-Zapata (eds., trads.). Avances interdisciplinarios para una comprensión crítica de la contabilidad. Textos paradigmáticos de las corrientes heterodoxas, 37-78. Bogotá: Escuela de Administración y Contaduría Pública, Universidad Nacional de Colombia y Departamento de Ciencias Contables, Universidad de Antioquia.

Colombia, Conpes 3582 de 2009, política nacional de ciencia, tecnología e innovación. Disponible en: http://www. colciencias.gov.co/normatividad/conpes3582-de-2009

Colombia, Ley 1286 de 2009, por la cual se modifica la Ley 29 de 1990, se transforma a Colciencias en Departamento Administrativo, se fortalece el Sistema Nacional de Ciencia, Tecnología e Innovación en Colombia y se dictan otras disposiciones. Diario Oficial, 47.241, 23 de enero de 2009. Disponible en: http://www. secretariasenado.gov.co/senado/basedoc/ ley_1286_2009.html\#1

Cruz-Kronfly, Fernando (1998). La tierra que atardece. Bogotá: Editorial Planeta.

Cruz-Kronfly, Fernando (2008). Del hombre como fin al hombre como medio en la pro- 
ducción. En Fernando Cruz-Kronfly (ed.). Racionalidad instrumental y gestión, 67-90. Colección Nuevo Pensamiento Administrativo, Cali: Universidad del Valle.

Cruz-Kronfly, Fernando (2010). Producir conocimiento es mirar de otro modo. En Claudia Barrios-Álvarez \& William Rojas-Rojas (comps.). Perspectivas críticas de la contabilidad contemporánea. Conjunciones y disertaciones: pensando la contabilidad en el siglo XXI, 13-17. Cali: Facultad de Ciencias Económicas y Administrativas, Pontificia Universidad Javeriana y Facultad de Ciencias de la Administración, Universidad del Valle.

Cubides, Humberto J.; Maldonado, Alberto; Machado, Marco; Visbal, Fernando \& Gracia, Édgar (1999). Historia de la contaduría pública en Colombia siglo XX: elementos para su interpretación. Bogotá: Fundación Universidad Central.

Cuevas-Mejía, John Jairo; Grajales-Quintero, Jhonny \& Usme-Suárez, Wilson Alexis (2013). Aproximación al rol de la información financiera elaborada con fines externos en un contexto de hibridaje cultural. Cuadernos de Contabilidad, 14 (36), 1045-1078. Disponible en: http://revistas.javeriana.edu. co/index.php/cuacont/article/view/7912

Derrida, Jacques (1997). Las pupilas de la universidad. El principio de razón y la idea de la universidad. En Jacques Derrida. Cómo no hablar y otros textos. Cristina de Peretti (trad.). Barcelona: Proyecto A. Disponible en: https://cv2.sim.ucm.es/moodle/file. php/11491/OtrosTextosFilosofYPolitica/Derrida-Las_pupilas_de_la_Universidad.pdf
Derrida, Jacques (2002). La universidad sin condición. Cristina de Peretti \& Paco Vidarte (trads.). Madrid: Trotta. Disponible en: http://sumak.cl/2AutoryExp/Derrida/ Derrida,\%20Jacques\%20-\%20La\%20 universidad $\% 20 \sin \% 20$ condicions $\% 20$ -\%20conferencia.pdf

Dufour, Dany-Robert (2007a). El arte de reducir cabezas. Sobre la servidumbre del hombre liberado en la era del capitalismo total. Buenos Aires: Paidós.

Dufour, Dany-Robert (2007b). Le Divin marché. La révolution culturelle libérale. Paris: Denoël.

Federación Internacional de Contadores (International Federation of Accountants, IFAC). (2008). Normas Internacionales de Formación 1-8. New York: Federación Internacional de Contadores (International Federation of Accountants/ IFAC). Disponible en: http://www.ifac. org/sites/default/files/downloads/Spanish_ Translation_Normas_Internacionales_de_ Formacion_2008.pdf

Finkielkraut, Alain (1999). La humanidad perdida. Barcelona: Anagrama.

Gadamer, Hans-Georg (1996). El estado oculto de la salud. Barcelona: Gedisa

García-Canclini, Néstor (2008). Diferentes, desiguales y desconectados: mapas de la interculturalidad. Barcelona: Gedisa. Disponible en: http://www. interculturalidadypatrimonio.cl/ wp-content/uploads/2014/09/ NGCDifsdesig_y_desc1.pdf

Gil, Jorge Manuel (2004). Los modelos contables y los estilos de administración en el es- 
tadio actual de la globalización económica: aportes para una revisión conceptual y referencias de su situación en América Latina. En Harold Álvarez-Álvarez, Jorge Manuel Gil, Édgar Gracia-López, Guillermo Martínez-Pino \& Olver Valencia Quijano. La contaduría pública en el nuevo entorno global: rutas y desviaciones, 15-44. Popayán: Editorial Universidad del Cauca.

Gómez-Villegas, Mauricio (2010). Dinámica de la concepción y la enseñanza de la teoría contable en Colombia (1970-2000): una exploración institucional. En Claudia Barrios-Álvarez \& William Rojas-Rojas (comps.). Perspectivas críticas de la contabilidad contemporánea. Conjunciones y disertaciones: pensando la contabilidad en el siglo XXI, 127-159. Cali: Facultad de Ciencias Económicas y Administrativas, Pontificia Universidad Javeriana y Facultad de Ciencias de la Administración, Universidad del Valle.

Gómez-Villegas, Mauricio \& Ospina, Carlos Mario (2009). Ampliando las fronteras en la disciplina contable: una introducción para la contextualización de los ejemplares heterodoxos. En Mauricio GómezVillegas \& Carlos Mario Ospina-Zapata (eds., trads.). Avances interdisciplinarios para una comprensión crítica de la contabilidad. Textos paradigmáticos de las corrientes heterodoxas, 13-35. Bogotá: Escuela de Administración y Contaduría Pública, Universidad Nacional de Colombia y Departamento de Ciencias Contables, Universidad de Antioquia.
González, William (2012). La investigación puesta a prueba por las ciencias humanas. ¿Qué universidad queremos?, 1. Cali, Colombia: Departamento de Filosofía, Universidad del Valle.

Gracia-López, Édgar (1998). El contexto internacional de la Contaduría Pública. Revista Porik An, 1 (1), 33-46.

Gracia-López, Édgar (2010). Problemáticas de la teoría e investigación contables. En Claudia Barrios-Álvarez \& William Rojas-Rojas (comps.). Perspectivas críticas de la contabilidad contemporánea. Conjunciones y disertaciones: pensando la contabilidad en el siglo XXI, 43-60. Cali: Facultad de Ciencias Económicas y Administrativas, Pontificia Universidad Javeriana y Facultad de Ciencias de la Administración, Universidad del Valle.

Grajales, Jhonny Steven (2007). Prejuicios hacia la contaduría pública: una mirada a la realidad desde la ficción literaria. Contaduría, Universidad de Antioquia, 51, 183-198. Disponible en: http://aprendeenlinea.udea.edu.co/revistas/index.php/cont/article/view/2155/1755

Higuera, Javier de la (2007). Estudio preliminar. En Michel Foucault. Sobre la ilustración. Madrid: Tecnos.

Hobsbawm, Eric (2000). Entrevista sobre el siglo XXI (al cuidado de Antonio Polito). Barcelona: Crítica.

Ladrière, Jean (1977). El reto de la racionalidad. La ciencia y la tecnología frente a las culturas. Madrid: Sígueme y Organización de las Naciones Unidas para la Educación, la Ciencia y la Cultura, UNESCO.

Lipovetsky, Gilles (2008) Los tiempos hipermodernos. Barcelona: Editorial Anagrama. 
López-Sánchez, Rogelio (2013). El

abstencionismo como fenómeno político en la sociedad contemporánea. Culturales, 1 (1), 53-68. Disponible en: http://www.scielo.org.mx/scielo. php?script $=$ sci_arttext $\&$ pid $=S 1870$ $11912013000100003 \& \ln g=e s \& t \operatorname{lng}=e s$

Marías, Javier (2013). Los enamoramientos. Madrid: Debolsillo.

McPhail, Ken (2002). La amenaza de los contadores éticos. Una aplicación del concepto de ética de Foucault a la educación contable y algunos pensamientos sobre el educar éticamente para los otros. Cuadernos de Contabilidad, 3 (15), 17-53. Disponible en: http:// cuadernosdecontabilidad.javeriana.edu.co/ vol3_n_15/vol3_15_1.pdf

Nussbaum, Martha (2005). El cultivo de humanidad. Barcelona: Paidós.

Ospina-Zapata, Carlos Mario (2006). Las tramas de la contabilidad. Trazos para quienes inician su formación en Contaduría Pública. Contaduría, Universidad de Antioquia, 48, 155-186.

Pesqueux, Yvon (2010). Los problemas actuales de la investigación en contabilidad y control: el problema de la norma. En Claudia Barrios-Álvarez \& William Rojas-Rojas (comps.). Perspectivas críticas de la contabilidad contemporánea. Conjunciones y disertaciones: pensando la contabilidad en el siglo XXI, 19-41. Cali: Facultad de Ciencias Económicas y Administrativas, Pontificia Universidad Javeriana y Facultad de Ciencias de la Administración, Universidad del Valle. Rojas, William (2002). La educación contable en Colombia 1960-2000: al servicio de la afraternidad económica moderna. Cuadernos de Administración, 18 (28), 17-43. Disponible en: http://cuadernosdeadministracion.univalle.edu.co/index.php/cuadernosadmin/article/view/1156

Rueda, Gabriel (2013). Editorial. El papel de las publicaciones en medio de las tensiones entre la investigación académica y la práctica contable. Cuadernos de Contabilidad, 15 (38), 11-15. Disponible en: http://revistas. javeriana.edu.co/index.php/cuacont/article/ view/11996/9813

Sousa-Santos, Boaventura de (1998). De la mano de Alicia. Lo social y lo político en la postmodernidad. Bogotá: Siglo del Hombre, Uniandes.

Sousa-Santos, Boaventura de (2004). La universidad en el siglo XXI. Para una reforma democrática y emancipadora de la universidad. Ramón Moncada-Cardona (trad.). Bogotá: Corporación Viva la Ciudadanía.

Steiner, George (1992). En el Castillo de Barba Azul, aproximación a un nuevo concepto de cultura. Barcelona: Editorial Gedisa.

Visbal, Fernando (1999). Las asociaciones gremiales de contaduría en el desarrollo de la profesión. En Humberto J. Cubides, Alberto Maldonado, Marco Machado, Fernando Visbal \& Édgar Gracia. Historia de la contaduría pública en Colombia siglo XX: elementos para su interpretación, 305-406. Bogotá: Departamento de Investigación, Fundación Universidad Central.

- Fecha de recepción: 09 de marzo de 2015

- Fecha de aceptación: 21 de mayo de 2015

- Disponible en línea: 30 de agosto de 2015 
328 / VOL. 16 / NO. 41 / MAYO-AGOSTO 2015

\section{Para citar este artículo}

Rojas-Rojas, William (2015). Lectoescritura y pensamiento crítico: desafío de la educación contable. Cuadernos de Contabilidad, 16 (41), 307-328.http://dx.doi. org/10.11144/Javeriana.cc16-41.lpcd 